\title{
Fibromyalgia in the mothers of the children with cerebral palsy, and determination of the related depression and anxiety situations
}

\author{
Şeyma Toy ${ }^{1},{ }^{\oplus}$, Ayşegül Beykumül ${ }^{1} \oplus, Z^{2}$ eynep Tuğçe Avcı ${ }^{1}$, Raikan Büyükavcı ${ }^{1 \oplus}$ \\ ${ }^{1}$ Department of Physical Medicine and Rehabilitation, İn̈̈ü University School of Medicine, Malatya, Turkey \\ ${ }^{2}$ Department of Anatomy, İnönü University School of Medicine, Malatya, Turkey
}

DOI: $10.18621 /$ eurj.424174

\begin{abstract}
Objectives: In this study, it was aimed to evaluate maternal functional status, quality of life, depression and anxiety measurements according to the child's functional level in the mothers, who were diagnosed with fibromyalgia syndrome (FMS), of children with cerebral palsy (CP).

Methods: Ninety-seven mothers diagnosed with FMS, whose children had CP, were included in the study. Children with CP were divided into two functional levels with the Gross Motor Function Classification System (GMFCS) as mild-moderate (level 1,2 and 3) and severe (level 4 and 5). On mothers, The Fibromyalgia Impact Questionnaire (FIQ) was used to assess the functional levels and quality of life, Beck Depression Inventory (BDI) was used to evaluate the depression level, and Beck Anxiety Inventory (BAI) was used to determine the anxiety level.

Results: The mean age of the 97 female patients participating in the study was $35.93 \pm 8.72$ years. According to GMFCS, $67 \%$ of children with CP were mild to moderate while $33 \%$ were severe. There was a significant positive correlation between GMFCS levels of children with CP and their mother's FIQ, BDI, and BAI scores $(p<0.05)$.

Conclusions: Maintaining the daily life of a child with $\mathrm{CP}$ is a parenting-focused situation. Especially it affects the mother physically and mentally. Our study suggests that the severe physical condition of the child with CP increases the mother's FIQ, depression, and anxiety. It has been determined that studies on CP should not ignore the parental factor as well as research on the disease itself.
\end{abstract}

Keywords: .cerebral palsy, depression, anxiety, fibromyalgia

Received: May 16, 2018; Accepted: September 6, 2018; Published Online: September 30, 2018

$\sim$ erebral palsy $(\mathrm{CP})$ is a persistent motion and posture disorder associated with damage to the brain that maintains its development [1]. Although rates vary according to different countries around the world, incidence in a prevalence study in Turkey was found as 4.4/1000 [2]. Many factors, such as clinical types, motor loss in the affected extremities, sensorial, com- municative, and mental disorders of the children with $\mathrm{CP}$ determine their ambulatory abilities and performance of their self-care skills. Treatment of the child with CP is multidisciplinary teamwork. This includes physiatrists, pediatricians, physiotherapists, orthopedists and neurosurgeons, educators, occupational therapists and speech therapists, and parents. However, at

Address for correspondence: Şeyma Toy, MD., İönü University School of Medicine, Department of Physical Medicine and Rehabilitation, Malatya, Turkey

E-mail: seymatoy44@gmail.com 
the center of the team is the family, especially the mother $[3,4]$. For this reason, maternal health is an essential parameter in the treatment of children with CP.

Fibromyalgia Syndrome (FMS) is a multisystemic disease characterized by chronic widespread musculoskeletal pain. There are regional studies on FMS prevalence in our country; for Diyarbakır region, this rate was determined as $8.8 \%$ [5]. It is seen more frequently in female gender and age range of 40-55 years. Many symptoms such as body pain, the absence of energy, stiffness, sleep disturbances, anxiety, depression, memory problems, balance problems, sensitivity to touching, heat, and sound are evaluated in FMS. In previous studies, the prevalence of anxiety and depression in FMS patients was found to be higher than in the healthy population [6]. Besides, widespread chronic pain, fatigue, sleep disturbance, and psychiatric symptoms disrupt the daily living activities and quality of life of patients [7].

In this study, we aimed to determine the relationship between the anxiety, depression level and quality of life of the FMS mothers with CP children and their children's functional status.

\section{METHODS}

Ninety-seven mothers, who were diagnosed with FMS, of the ninety-seven childrren with $\mathrm{CP}$ who received rehabilitation treatment at the Inönü University Turgut Özal Medical Center Physical Medicine and Rehabilitation Unit were included in the study. Ethic committee approval (2016/106) of the study was obtained from the Malatya Clinical Research Ethics Committee. All patients included in the study were informed about the study and received their approval.

Mothers, who were between 18-60 years of age and who had FMS diagnosis according to the 2013 ACR diagnostic criteria, of the children with $\mathrm{CP}$ were included in the study. Having physical therapy and medical treatment for FMS in the last six months, the presence of cervical disc hernia, radiculopathy and myelopathy story, antidepressant treatment within the last six months, and the presence of more than one child with $\mathrm{CP}$ were defined as exclusion criteria.

In the assessment of the patients diagnosed with FMS; the demographic data of the mother and the child, CP type of the child and the Gross Motor Function Classification System (GMFCS) were evaluated by the same physical medicine and rehabilitation specialist. The way the child was carried by the mother, the duration, and frequency of the home exercise and the use of orthosis were recorded.

\section{Gross Motor Function Classification System (GMFCS)}

GMFCS is a standard measurement method for children with $\mathrm{CP}$ who divides to the levels according to the motor function. Children in the first level are independent of the motor functions, while children in the fifth level are defined as the dependent [8]. In our study, GMFCS levels 1, 2 and 3 were defined as mildmoderate, while levels 4 and 5 were defined as the severe group.

\section{Functional Assessment and Quality of Life}

In order to evaluate the quality of life and functional status in FMS in our study, The Fibromyalgia Impact Questionnaire (FIQ) which Turkish validity and reliability was shown by Sarmer et al. [9] was used. At this scale, ten different features are measured: physical function, feeling good or not, not being able to go to work, difficulty at work, pain, fatigue, morning fatigue, stiffness, anxiety, and depression. The maximum score is 100 . While an average patient with FMS receives 50 points, a severely affected patient usually scores over 70 [10].

\section{Depression Assessment}

The presence and severity of depression were determined using the Beck Depression Inventory (BDI) [11]. This scale which Hisli [12] made its validity and reliability in our country in 1988 , consists of 21 items. Each item consists of 4 sentences, ordered by neutral ( 0 points) and severest ( 3 points). In our study, 0-9 points were assessed as not depressed, 1016 points as mild depression, $17-29$ points as moderate depression and $\geq 25$ points as severe depression [13].

\section{Anxiety Assessment}

Beck Anxiety Inventory (BAI) was used to determine the anxiety level. This scale which was developed by Beck et al. [11] in 1988 consists of a total of 21 items. Each item is scored between 0-3 with a Likert type scale. The total score range is 0-63. 0-7 
points are considered normal, 8-15 points mild, 16-25 points moderate, and $\geq 26$ points for severe anxiety. Validity and reliability study for the Turkish population was done by Ulusoy et al. [14]..

\section{Statistical Aanalysis}

Statistical Package for the Social Sciences (SPSS) 17 Windows software program was used for statistical analysis. The mean of the quantitative data was expressed as median (minimum-maximum) and mean \pm standard deviation. Qualitative data were expressed as number (n) and percentage (\%). The KolmogorovSimirnov test assessed the suitability of the normal distribution of measurable values. Pearson correlation analysis was performed for the analysis of the linkages of the variables. A $p$ value $<0.05$ were considered statistically significant.

\section{RESULTS}

The mean age of the 97 female patients

Table 1. Sociodemographic sharacteristics of the mother

\begin{tabular}{lc}
\hline Characteristics & Data \\
\hline The average age $($ mean \pm SD) & $35.93 \pm 8.72$ \\
Age distribution, $\mathrm{n}(\%)$ & $85(87.6)$ \\
$\leq 44$ Years & $12(12.4)$ \\
$>44$ Years & $14(14.4)$ \\
Education status, $\mathrm{n}(\%)$ & $42(43.3)$ \\
Not literate & $10(10.3)$ \\
Primary school & $21(21.6)$ \\
Mid school & $10(10.3)$ \\
High school & \\
University & $7(7.2)$ \\
Yes & $90(92.8)$ \\
No & \\
Working Status, $(\%)$ & \\
Does She Get Physical Help For & $26(26.8)$ \\
Caring?, $\mathrm{n}(\%)$ & $71(73.2)$ \\
Yes & \\
No & \\
Does She Get Exercises Done at & $84(86.6)$ \\
Home?, $(\%)$ & $13(13.4)$ \\
Yes & \\
No & $13(13.4)$ \\
The frequency of Exercise at & $55(56.7)$ \\
Home, n $(\%)$ & $25(25.8)$ \\
Not doing & $4(4.1)$ \\
5-30 min. &
\end{tabular}

$\mathrm{SD}=$ Standart deviation
Table 2. Socio-demographic characteristics of children with $\mathrm{CP}$

\begin{tabular}{|c|c|}
\hline Characteristics & Data \\
\hline \multicolumn{2}{|l|}{ Gender, n (\%) } \\
\hline Girl & $51(52.6)$ \\
\hline Boy & $46(47.4)$ \\
\hline The average age (mean \pm SD) & $6.42 \pm 4.72$ \\
\hline \multicolumn{2}{|l|}{ Age distribution, $\mathrm{n}(\%)$} \\
\hline 0-2 Years & $23(23.7)$ \\
\hline 3-6 Years & $38(39.2)$ \\
\hline 7-12 Years & $21(21.6)$ \\
\hline 13-18 Years & $15(15.5)$ \\
\hline Weight $($ mean $\pm \mathrm{SD})$ & $23.28 \pm 13.9$ \\
\hline Height (mean \pm SD) & $111.62 \pm 26.95$ \\
\hline \multicolumn{2}{|l|}{ GMFCS level, n (\%) } \\
\hline I & $14(14.4)$ \\
\hline II & $31(32)$ \\
\hline III & $20(20.6)$ \\
\hline IV & $21(21.6)$ \\
\hline $\mathrm{V}$ & $11(11.3)$ \\
\hline \multicolumn{2}{|l|}{ Orthotic use, n (\%) } \\
\hline Yes & $41(42.3)$ \\
\hline No & $56(57.7)$ \\
\hline \multicolumn{2}{|l|}{ Carriage way, n (\%) } \\
\hline On lap & $63(64.9)$ \\
\hline Device assisted & $34(35.1)$ \\
\hline \multicolumn{2}{|l|}{ Special education, $\mathrm{n}(\%)$} \\
\hline Yes & $65(67)$ \\
\hline No & $32(33)$ \\
\hline
\end{tabular}

$\mathrm{SD}=$ Standart deviation, GMFCS = Gross motor function classification scale

participating in the study was $35.93 \pm 8.72$ years. Fourty-two $(43.3 \%)$ mother had gone to primary school, and $92.8 \%$ were not working. Although $73.2 \%$ did not receive physical help in the care of the child, $86.6 \%$ of them have their child regularly exercised. Sociodemographic data are summarized in Table 1. Fifty-one $(52.6 \%$ ) children with CP were girls, $47.4 \%$ were boys. The mean age of the children was $6.42 \pm$ 4.72 years. According to GMFCS, $67 \%$ were mild to moderate while $33 \%$ were severe. Table 2 summarizes the sociodemographic characteristics of children with CP.

Table 3. Scale scores

\begin{tabular}{lcc}
\hline Parameter & Mean \pm SD & $\boldsymbol{p}$ value \\
\hline FIQ & $41 \pm 21.23$ & $<\mathbf{0 . 0 0 1}$ \\
BDI & $15.32 \pm 12.07$ & $<\mathbf{0 . 0 0 1}$ \\
BAI & $15.92 \pm 13.95$ & $<\mathbf{0 . 0 0 1}$ \\
\hline FIQ = The Fibromyalgia Impact Questionnaire, BDI = Beck \\
Depression Inventory, BAI = Beck Anxiety Inventory, SD = \\
Standart deviation
\end{tabular}


Table 4. Evaluation of some parameters of patients with FIQ $<50$ and FIQ $\geq 50$ scores

\begin{tabular}{|c|c|c|c|}
\hline Mother age (n) & $\begin{array}{l}\mathrm{FIQ}<50(\mathrm{n}) \\
\end{array}$ & FIQ $>50(n)$ & TOTAL \\
\hline$\leq 44$ Years & 58 & 27 & 85 \\
\hline$>44$ Years & 5 & 7 & 12 \\
\hline \multicolumn{4}{|l|}{ Child age (n) } \\
\hline 0-3 Years & 16 & 7 & 23 \\
\hline 4-6 Years & 24 & 14 & 38 \\
\hline 7-12 Years & 11 & 10 & 21 \\
\hline 13-18 Years & 12 & 3 & 15 \\
\hline \multicolumn{4}{|l|}{ Depression (n) } \\
\hline No (0-9 Points) & 22 & 0 & 22 \\
\hline Yes (10-63 Points) & 41 & 34 & 75 \\
\hline \multicolumn{4}{|l|}{ Anxiety (n) } \\
\hline No (0-7 Points) & 25 & 3 & 28 \\
\hline Yes (8-63 Points) & 38 & 31 & 69 \\
\hline \multicolumn{4}{|l|}{ Exercise frequency(n) } \\
\hline 5 - 30 Min. & 39 & 16 & 55 \\
\hline 31 - 60 Min. & 12 & 13 & 25 \\
\hline 61 - 90 Min. & 2 & 10 & 4 \\
\hline Never & 10 & 2 & 13 \\
\hline \multicolumn{4}{|l|}{ Carriage way (n) } \\
\hline With Device & 18 & 16 & 34 \\
\hline On Lap & 18 & 45 & 63 \\
\hline \multicolumn{4}{|l|}{ Level (n) } \\
\hline Mild-Moderate (I-III) & 53 & 12 & 65 \\
\hline Severe (IV-V) & 10 & 22 & 32 \\
\hline \multicolumn{4}{|l|}{ Job (n) } \\
\hline Not working & 59 & 31 & 90 \\
\hline Working & 4 & 3 & 7 \\
\hline \multicolumn{4}{|l|}{ Special education (n) } \\
\hline Not Receiving & 18 & 14 & 32 \\
\hline Receiving & 45 & 20 & 65 \\
\hline \multicolumn{4}{|l|}{ Orthotic use (n) } \\
\hline Yes & 22 & 19 & 41 \\
\hline No & 41 & 15 & 56 \\
\hline
\end{tabular}

The results of the FIQ, BDI, and BAI of the mothers are shown in Table 3 . Table 4 shows that mothers with FIQ $\geq 50$ experience more severe depression and anxiety than those with FIQ $<50$, have more extended hours of exercise for their children, often carry them on their lap, and children have a higher GMFCS score.

There was a statistically significant difference between the two groups when the results of FIQ, BDI, and BAI were compared between the mild-tomoderate group levels and the severe group levels of children according to GMFCS (Table 5).

Tablo 5. Relationship between GMFCS levels of children with CP and FIQ, BDI, and BAI levels assessed in the mothers

\begin{tabular}{lccc}
\hline GMFCS & $\begin{array}{c}\text { Mild-Moderate Level } \\
(\text { Level 1, 2, 3) }\end{array}$ & $\begin{array}{c}\text { SevereLevel } \\
(\text { Level 4, 5) }\end{array}$ & $p$ value \\
\hline FIQ & $34.54 \pm 16.67$ & $55.79 \pm 22.59$ & $<0.05$ \\
BDI & $12.92 \pm 10.49$ & $20.21 \pm 13.67$ & $<0.05$ \\
BAI & $12.93 \pm 11.94$ & $22.03 \pm 15.85$ & $<0.05$ \\
\hline
\end{tabular}

Data are given as mean \pm standard deviation. FIQ $=$ The Fibromyalgia Impact Questionnaire, BDI = Beck Depression Inventory, BAI = Beck Anxiety Inventory, GMFCS = Gross motor function classification scale 


\section{DISCUSSION}

This study aimed to show the effect of the dependent functional status of children with $\mathrm{CP}$ on the quality of life and functional status, depression, and anxiety in FMS-diagnosed mothers and concluded that this had a negative effect.

The treatment process for a child with $\mathrm{CP}$ is a long and challenging process. In this process, the familybased multidisciplinary approach is the basis of treatment. The fact that parents are always involved with active participation at every stage of treatment and in the center of the rehabilitation process presents a number of challenges and limitations, especially in the lives of mothers who undertake the primary care. However, studies on children with CP have mostly focused on the disease itself and have been relatively neglected the family side. In the literature review, limited studies were made on the quality of life of mothers of CP children. In the study performed by Ones et al. [15], the mothers of children with CP and healthy children's mothers were compared, and the quality of life in the mothers of children with $\mathrm{CP}$ were found to be significantly lower. In a study in Bangladesh, Mobarak et al. [16] found that $41.8 \%$ of 91 mothers of the children with $\mathrm{CP}$ had a risk of psychiatric morbidity. Eker and Tüzün [17] examined the quality of life difference between the mothers who have children with $\mathrm{CP}$ and the mothers with minor health problems (fever, cough, diarrhea) with Short Form-36 (SF-36). Comparisons were made both in comparison to two groups and when children with $\mathrm{CP}$ were self-rated according to GMFCS; significant differences were found in all parameters except for the physical function subsystem of SF-36 [17]. In FMS patients, depression and sleep disturbances are seen at high rates and quality of life is already very low [7]. At the same time, due to both physical and psychological deprivation in many areas such as heavy lifting, turning, bathing, supporting toilet needs, dressing, feeding, supporting sleeping needs and helping movements, which are essential for the child's caring tasks, the quality of life for the FMS-diagnosed mothers of the children with $\mathrm{CP}$, is expected to be lower. In this context, we have found that the quality of life and the functional status of the mothers of children with $\mathrm{CP}$, who already have FMS diagnosis, are closely related to the increased dependence of the child in our study.

On the other hand, FMS is a multisystemic disease with chronic widespread musculoskeletal pain. Musculoskeletal pain in mothers of children with $\mathrm{CP}$ is among the problems they often face because they cover all the needs of the child and are exposed to physical difficulties. However, there is a limited number of studies evaluating the musculoskeletal system in the literature. In the study by Terzi and Tan [18], musculoskeletal system pain and related factors were investigated in the mothers of children with $\mathrm{CP}$ and the total number of children, the age of the child with $\mathrm{CP}$, functional level and the depression level of the child were found to be independent risk factors. In a study made by Prudente et al. [19], following a 10month rehabilitation program, the motor function of the children with $\mathrm{CP}$ and maternal quality of life were investigated, and improvement in gross motor functions was found after recovery and rehabilitation in children and there was a corresponding decrease in the lower body pain of the mothers.

We evaluated our patients with BDI and BAI, which are commonly used in depression and anxiety frequently accompanies the disease, which is also included in the 2013 ACR fibromyalgia diagnostic criteria. Statistically significant high scores were found when the depressed values were compared between mothers with healthy children and those with CP children in the study made by Terzi et al. [18]. Rosenbaum has shown that parents of the children with chronic illness experience twice as much anxiety and depression than parents with healthy children [20]. Parents of children with chronic illness are at risk of losing their psychosocial health. Interventions to protect and improve their health are urgently needed [21]. Mothers of children with CP can not only try to overcome the difficulties and complications of their children's condition but also face the difficulties of not meeting their social needs [15]. The association of these problems is similar to the other studies in the literature, and in our study, we found that the results of the high GMFCS and FIQ, BDI, BAI scores showed a significant positive correlation.

\section{CONCLUSION}

In conclusion, we found that mothers of the 
children with $\mathrm{CP}$ had increased fibromyalgia, depression and anxiety as GMFCS scores of the children increased. We believe that interventions to protect and improve the physical and psychosocial well-being of parents and parent-focused literature studies will increase the quality of life for children with CP.

\section{Authorship declaration}

All authors listed meet the authorship criteria according to the latest guidelines of the International Committee of Medical Journal Editors, and all authors are in agreement with the manuscript.

\section{Authors' Contributions}

Research Design: ŞT, AB, ZTA; Data Collecting: ŞT, ZTA; Literature Review: ŞT; Statistical Analysis: $\mathrm{AB}, \mathrm{RB}$

\section{Conflict of interest}

The authors disclosed no conflict of interest during the preparation or publication of this manuscript.

\section{Financing}

The authors disclosed that they did not receive any grant during conduction or writing of this study.

\section{REFERENCES}

[1] Berker N, Yalçın S. The HELP Guide to Serebral Palsy 2005;1-144.

[2] Beyazova M, Gökçe Kutsal Y. Serebralpalsi. Fiziksel Tıp ve Rehabilitasyon Güneş Tıp Kitabevleri. 2011;2681-2724.

[3] Smith CL. Pediatric rehabilitation. In: Goodgold J, ed. Rehabilitation Medicine, 1st ed. St. Louis: CV Mosby; 1988:40724.

[4] Murphy K, Molnar GE, Lankasky K. Medical and functional status of adults with cerebral palsy. Dev Med Child Neurol 1995;37:1075-84.

[5] Turhanoglu AD, Yılmaz Ş, Kaya S, Dursun M, Kararmaz A, Saka G. The epidemiological aspects of fibromyalgia syndrome in adults living in Turkey: a population based study. J Musculoskelet Pain 2008;16:141-147.
[6] McBeth J, Silman AJ. The role of psychiatric disorders in fibromyalgia. Curr Rheumatol Rep 2001;3:157-64.

[7] Özcan DS, Aras M, Köseoğlu BF, Şentürk Güven Ş. [Quality of life and associated conditions in women with fibromyalgia syndrome]. Türk Osteoporoz Dergisi 2013;19:42-7. [Article in Turkish]

[8] Wood E, Rosenbaum P. The Gross Motor Function Classification System for cerebral palsy: a study of reliability and stability over time. Dev Med Child Neurol 2000;42:292-6.

[9] Sarmer S, Ergin S, Yavuzer G. The validity and reliability of theTurkish version of the Fibromyalgia Impact Questionnaire. Rheumatol Int 2000;20:9-12.

[10] Burckhardt CS, Clark SR, Bennett RM. The fibromyalgia impact questionnaire: development and validation. J Rheumatol 1991;18:728-33.

[11] Beck AT, Ward CH, Mendelson M, Mock J, Erbaugh J. An inventory for measuring depression. Arch Gen Psychiatry 1961;4:561-71.

[12] Hisli N. Beck Depresyon Envanteri'nin geçerliği üzerine bir çalışma. Psikoloji Dergisi 1998;6:118-26.

[13] Kapci EG, Uslu R, Turkcapar H, Karaoglan A. Beck Depression Inventory II: evaluation of the psychometric properties and cut-off points in a Turkish adult population. Depress Anxiety 2008;25:104-10.

[14] Ulusoy M, Sahin NH, Erkmen H. Turkish version of the Beck Anxiety Inventory: psychometric properties. J Cogn Psychother 1998;12:163-72.

[15] Ones K, Yilmaz E, Cetinkaya B, Caglar N. Assessment of thequality of life of mothers of children with cerebralpalsy (primary caregivers). Neurorehabil Neural Repair 2005;19:2327.

[16] Mobarak R, Khan NZ, Munir S, Zaman SS, McConachie H. Predictors of stress in mothers of children with cerebralpalsy in Bangladesh. J Pediatr Psychol 2000;25:427-33.

[17] Eker L, Tüzün EH. An evaluation of quality of life of mothers of children with cerebral palsy. Disabil Rehabil 2004:26;1354-9.

[18] Terzi R, Tan G. Musculoskeletal system pain and related factors in mothers of children with cerebral palsy. Agri 2016;28:18-24.

[19] Prudente CO, Barbosa MA, Porto CC. Relation between quality of life of mothers of children with cerebral palsy and the children's motor functioning, after ten months of rehabilitation. Rev Lat Am Enfermagem 2010;18:149-55.

[20] Rosenbaum PL. Prevention of psychosocialproblems in children with chronic illness. CMAJ 1988;139: 293-5.

[21] Cheshire A, Barlow JH, Powell LA. The psychosocial wellbeing of parents of children with cerebral palsy: a comparison study. Disabil Rehabil 2010;32:1673-7. 